\title{
Corrigendum
}

\section{Trust in UK financial services: A longitudinal analysis}

Christine Ennew, Harjit Sekhon and Husni Kharouf

Journal of Financial Services Marketing (2011) 16, 170. doi:10.1057/fsm.2011.16

The correct attribution for the above article should be:

Christine Ennew, Harjit Sekhon and Husni Kharouf, 'Trust in UK financial services: A longitudinal analysis', Journal of Financial Services Marketing, 16(1): 65-75 (June 2011). doi: 10.1057/fsm.2011.8. 